\title{
The Anger-Aggression Bidirectional-Causation (AABC) Model's Relevance for Dyadic Violence, Revenge and Catharsis
}

\section{Vladimir J Konečni*}

Department of Psychology, University of California, San Diego, California 92093, USA

\begin{abstract}
In this article, the multifaceted theoretical underpinnings of V. J. Konečni's Anger-Aggression BidirectionalCausation $(A A B C)$ model of interpersonal aggression are described, along with a large body of supporting data, mostly from laboratory experiments. The AABC model's utility in the clarification of several complex issues of long standing in various scholarly domains is discussed, such as: Catharsis and the "cathartic effect"; adaptationist accounts of revenge; and intrafamilial dyadic violence.
\end{abstract}

Keywords: Anger; Aggression; Revenge; Anger-aggression Bidirectional-causation model; AABC model; Catharsis; Cathartic effect; Dyadic violence

\section{Introduction}

In a recent article on family violence, Finkenauer et al. [1] invoked a host of distal factors (societal, structural, personality), but failed to address a frequent and potentially crucial proximal cause - the dyadic aggression sequence - of which the main components are provocation, anger, and retaliation. A detailed analysis of the aggression sequence, including the behavioral and physiological consequences of revenge, was, for perhaps understandable reasons, also missing in the recent adaptationist discussion of the revenge and forgiveness systems by McCullough et al. [2]. Yet the culmination of numerous aggressionrelated exchanges between members of a dyad (consisting of a couple, parent and offspring, and other relations), repeated over protracted time periods, may be the particularly deleterious anger-free preemptive strikes. The ingredients of an aggression series, its specific content and form, may be at the core of intrafamilial violence and offer insights regarding the possibilities of treatment tailored for dyads.

One purpose of this article is to review the evidence for the arguably key aspect of an aggression sequence, the "cathartic effect" (defined below), within Konečni's [3-5] Anger-Aggression BidirectionalCausation (or AABC) model. The second purpose is to contribute to, and hopefully extend, the systemic and the adaptationist accounts of provocation, revenge, and their roles in the dynamics of dyadic intrafamilial violence.

\section{The Relevant Aspects of Interpersonal Aggression}

The type of aggressive behavior with which this article is concerned is interpersonal, face-to-face, infliction of harm (or as close to that as one can come in laboratory settings), preceded by a pronounced emotional state, anger. One must immediately acknowledge that anger is largely absent in many instances of human aggression (e.g., someone's initiation into a street gang by violence; a pilot's bombardment of civilian targets from five kilometers), and this "instrumental," arguably cold-blooded, violence is not the subject of inquiry here. Despite the superficial similarity, such aggressive activity must be distinguished from the anger-free preemptive strikes, mentioned above, a condition to which a dyad arrives only after a prior series of "hot-blooded" exchanges. Most of the author's experimental work to which reference will be made has involved the (alleged) infliction of physical harm and he has clearly distinguished [3,4], on empirical and theoretical grounds, among physical aggression, verbal aggression, play and fantasy aggression, the mere observation of aggressive activity, and so on [6-10].

\section{The Relevant Aspects of Anger and PEEM}

Anger is a pronounced, and reliably reportable and observable, emotional state with numerous antecedents, concomitants, and consequences [11-16]. In the present author's experimental work and theoretical writing, anger has been viewed in the context of his Prototypical Emotion-Episode Model, or PEEM [17]. PEEM is concerned with the following events and processes, among others: Normative and attributive evaluation, and comprehension of the initial event (for example, an insult - a prototypical "ego-thwarting," socially inflicted, aversive stimulus); facial and postural cues; the fluctuations of (sympathetic) physiological arousal; and the monitoring of various internal cues, and the integration of these with the external-event cues ("emotion-labeling").

Although the experimental demonstrations by Schachter and Singer [18] have been sharply criticized [19,20], Schachter's core theoretical ("two-factor") proposal [21] has not been seriously challenged - that once an emotion has been identified ("labeled") by the experiencing person, the level of arousal largely governs the intensity of the emotion. Furthermore, once a person has been, for example, insulted, a further increment in arousal, which is soon afterwards induced by other, neutral, means, such as loud and complex music [16], or physical exercise [22,23], contributes in an additive manner to the overall anger, even though by themselves these neutral events are not anger-inducing. When, however, physical exercise precedes the insulting event, its arousingness contributes far less to the degree of subsequent anger [23]. Finally, due to the homeostatic regulation of arousal fluctuations,

*Corresponding author: Vladimir J. Konečni, Department of Psychology, University of California, San Diego, California 92093, USA, Tel: (858) 534-3000, E-mail: vkonecni@ucsd.edu

Received November 20, 2015; Accepted November 27, 2015; Published December 05, 2015

Citation: Konečni VJ (2015) The Anger-Aggression Bidirectional-Causation (AABC) Model's Relevance for Dyadic Violence, Revenge and Catharsis. Abnorm Behav Psychol 1: 104. doi:10.4172/abp.1000104

Copyright: @ 2015 Konečni VJ. This is an open-access article distributed under the terms of the Creative Commons Attribution License, which permits unrestricted use, distribution, and reproduction in any medium, provided the original author and source are credited. 
the level of arousal and the degree of anger predictably decrease with the passage of time $[3,24,25]$.

With regard to the emotion-identification (emotion labeling) issue, PEEM specifies a set of cognitive operations that are necessary for a person to infer, with confidence, that he or she is experiencing a pronounced, phenomenologically distinct, emotional state, such as anger or fear or joy [16]. The operations in question are monitoring, interpretation, and integration of information. Furthermore, there are two sequential interpretation components of PEEM. In the first, the information in the external event is analyzed, especially in terms of attribution theory [26]. Does the event have a natural or man-made origin? If man-made, is it accidental or intentional? If intentional, is it normative or counter-normative? And, in the case of anger, are someone's words a well-intentioned joke or an insult? Who is "someone" responsible for the insult? From an adult's viewpoint, is the speaker a 12-year-old boy or a powerful superior - so, anger or fear? From a 12-year-old boy's angle, does the insult come from his younger brother or his father? In short, the emotional-label inference depends on "causal assignment" or "causal explanation" [27]. The second distinct occurrence of interpretation is concerned with the monitored internal events - interoceptive feedback regarding arousal fluctuations; proprioceptive feedback from the facial musculature [28]; and postural cues - all of which are integrated in arriving at emotional identification or label.

An important aspect of PEEM is recursiveness, a feature that is meant, among other issues, to handle successive reinterpretations of the external event as it changes or develops. Words that are interpreted as insulting and lead to anger may be quickly followed by a disarming apology or clarification by the speaker, which would make anger be relabeled to, for example, mirth and cause arousal to dissipate very quickly. Also, the developing external event may demand urgent action, so that what begins as a mixed emotion, for instance, of anger and fear, is reinterpreted as one - the dominant alternative.

\section{Catharsis and the "Cathartic Effect"}

Both of these concepts have been discussed in detail by the author in various articles $[3-5,15,29]$. Catharsis, especially in its "hydraulic" form, has been severely criticized from various perspectives [30] and flagrantly misused in self-help manuals. With reference to experimentation, one of the most serious and frequent conceptual errors committed by researchers has been to regard the various substitute-target and vicarious aggressive activities as functionally equivalent to the infliction of physical injury - indeed, to regard them as "aggressive" (or "cathartic") at all.

The present author has attempted to avoid the mentioned conceptual pitfalls and has defined the "cathartic effect" as simply an empirically observable fact: When genuinely angry persons are given the opportunity to hurt (allegedly) the individual who insulted them, the amount of their subsequent (residual) aggression toward the same person is sharply reduced in comparison to persons who did not have the opportunity to retaliate - in fact, reduced to the level displayed by those who were not insulted at all beforehand [3]. These clear and replicable findings, and the underlying theoretical assumptions, have been incorporated in the AABC model.

Despite such findings, and warnings to the effect that definitions should be made explicit and concepts transparent when carrying out catharsis-related research, there have been subsequent experiments characterized by inadequate experimental procedures that largely tested straw versions of "catharsis" [31-33]. Such studies were recently criticized by Konečni [34], not only on methodological and conceptual grounds, but also with regard to their backdrop, colored by political and socio-cultural bias.

\section{The AABC Model: Assumptions, Provisos, Research Paradigm, Predictions}

The AABC model of interpersonal aggression was formulated only in 2012 by the author [5], but a detailed survey was published already in 1984 [4] of a very large body of relevant field and, especially, laboratory work by numerous investigators, including the author. The model is chiefly concerned with the various antecedents (especially anger) and consequences of face-to-face infliction of injury.

The two-way causal link (bidirectional causation) between the degree of anger and the amount of aggressive behavior that is performed refers to two related propositions. The first is that the higher the degree of anger, the greater the amount of aggression that will ensue, all else equal. The second is that aggressive actions performed by angry individuals against the human cause of their anger reduces, all else equal, their degree of felt anger, by virtue of eliminating or subduing the noxious external stimuli and thus decreasing the physiological justification for the angry state. The theory-imposed qualifications of this second proposition, the reverse causal link, are that a person's aggressive acts may reduce his or her anger (which is hypothetically mediated by the level of physiological arousal being lowered) provided that these acts: (a) are preceded by anger; (b) have the (human) source or instigator of anger as the target; (c) inflict harm to the target (or at least appear to the aggressor to do so), and (d) are not immediately followed by a further induction of anger, retaliation, or other aversive events. We shall return to these provisos in Section VI.5.

In the author's laboratory, the most relevant data were obtained by means of a three-stage research paradigm $[3,5]$. In a typical stage 1 , IO, the initial offender (that is, the experimenter's well-trained "accomplice", who would next himself or herself become the target), insults, in a standardized manner, the unsuspecting research participant (RP). In stage 2 (the "revenge" period), by following instructions on a bogus task, RP retaliates against IO, for example, by administering to this person a fixed number of (fictitious) electric shocks ("painful, but not causing injury"). Finally, in stage 3, RP's willingness to engage in additional ("residual") behavioral aggression against IO is measured by means of a specially designed pseudo-creativity test. In these experiments, there were numerous control conditions for all three research stages. For instance, in stage 1, there was the condition of $\mathrm{RP}$ being anger-free. In stage 2, the type and duration of interpolated activity were varied, such as aggression against a substitute target ("scapegoat") and mathematical tasks to minimize rumination. Finally, in stage 3, RP's residual aggression was measured when directed at substitute targets. In addition to the main dependent measure, which was RP's residual aggression toward IO, measurements of physiological arousal (blood pressure, heart rate, galvanic skin response, etc.) and a variety of verbal ratings were obtained in a methodologically careful manner, avoiding order and sequence effects, and other confoundings.

\section{The AABC Model: Experimental Findings}

A convincing amount of experimental support has been obtained in various laboratories for all components of the AABC model.

1. That noxious social stimulation, both of the insult ("ego threat") and "blocked goal" kinds, results in statistically significant increases in 
systolic blood pressure and heart rate, has been amply demonstrated, for instance, by Hokanson and his colleagues [35-37], and also by the present author in his extensive pilot (procedure pretesting) studies leading to various behavioral aggression experiments. In all of these and numerous other studies, noxious instigations also resulted in RPs' significantly more intense anger (as measured by self-ratings, in interviews, and observationally).

2. RPs who had been made angry by insults or capriciously blocked goals in carefully rigged experimental situations subsequently physically aggressed significantly more against IOs - in terms of "shocks" or "blasts of noise" - than did nonangered control RPs $[3,4,15,16,29]$.

3. After the angered RPs had physically retaliated against IO, they subsequently displayed significantly less behavioral aggression against IO than did the equally angered RPs without the prior retaliation experience $[3,4,15,38]$. This basic, experimentally demonstrated, cathartic effect was anticipated by Plato some 2,400 years ago: "If one man is angry with another, he can take it out of him on the spot, and will be less likely to pursue the quarrel further" [39]. In fact, the amount of residual aggression in the principal experimental group (insulted retaliators) in Konečni's experiments was, on the average, no greater than that in the nonangered control group $[3,15]$. Significantly, as predicted by the AABC model, all of the above results were paralleled by those in terms of psychophysiological measures in other experiments [35-37]. In addition, certain correct predictions could be made only on the basis of the cathartic effect within the AABC model - for instance, regarding alcohol intake and music choice. Insulted RPs, who had had the opportunity to retaliate, consumed significantly less alcohol than did the equally insulted ones without the retaliation opportunity [40]. Also, as predicted, whereas insulted RPs who had had a retaliation opportunity later behaved like the controls and chose simple and complex auditory stimuli equally often, insulted RPs without a retaliation opportunity shunned complex auditory stimulation $[41,42]$.

4. Although there are data showing that angered RPs' aggression against a person unrelated to IO ("scapegoat") reduces their subsequent aggression against IO [15,43], such "displaced" aggression, which obviously cannot be considered a genuine retaliatory act, has a much weaker effect at the group mean level than does retaliation against IO in the interpolated period (stage 2). In addition, angered RPs' displaced aggression against a person unrelated to IO did not reduce their systolic blood pressure in one study [43]. In another experiment, aggression against IO's declared "assistant" resulted in blood pressure readings that were halfway between those for the direct-aggression group and the no-aggression control, but this displaced-aggression effect was not statistically significant [37].

5. As for the findings that address the second proposition (reverse causal link) of the AABC model (Section V.), the following ones are relevant: (a) when aggressive actions in stage 2 are not preceded by anger (in stage 1), participants' subsequent aggression in stage 3 is not decreased in comparison to controls without a prior aggression experience $[3,10,15,23,38]$; this is in line with the theory - emotionfree aggression is likely to lead to more aggression; (b) there is, for all practical purposes, no support in the literature for the notion that angered persons' "aggression" against inanimate targets reduces their subsequent arousal, anger, or aggression; when the target of aggression is a human other than the anger instigator, the cathartic effect is behaviorally weak and physiologically nonexistent [15,37,43]; (c) one experiment, in which participants' beliefs were manipulated about the probability $(0.9,0.5$, or 0.1$)$ that IO would receive the (alleged) shocks they were "administering", decisively demonstrated that the cathartic effect depended, in a manner that was predicted by the AABC model, on harm actually being inflicted by RPs' actions [44]; and (d) there are insurmountable logistical difficulties in attempting to study in the laboratory any anger induction, revenge, and other aversive evens befalling the participants beyond the already very complex three-stage design; however, a discussion of the sequence of aggressive actions in dyads will be resumed later.

\section{Why is Aggression Exceptionally Effective in Reducing Anger?}

It is a truism that social aversive events (i.e., aversive events caused by other people) often have a profound effect on a person exposed to them, especially if others' actions are perceived as capricious or arbitrary [27] and performed with the intent of inflicting physical, economic, or psychological harm. One immediate and important consequence of such events is a dramatic increase in the level of arousal, frequently labeled as anger - a consequence that is particularly well documented, as we have seen, in the case of humiliating behavior and insults. The insult-induced elevation of arousal (which is in itself demonstrably aversive) is likely to persist for the duration of noxious stimulation. Once insults have ceased or their source has been otherwise removed from the proximity of their target, the latter's arousal level - as was mentioned earlier - gradually subsides toward the baseline, barring additional aversive events or rumination-induced arousal-level increases. It is maladaptive for arousal level to remain excessively high for long periods after the noxious stimulation has ceased and it is self-evident that most people exposed to verbal abuse would be highly motivated to bring about as quick as possible a termination of such an event. It is also self-evident that actions that are successful in terminating external noxious stimulation are followed, closely in time, by the onset of homeostatic arousal-decay processes.

Laboratory experiments have shown that physical retaliation toward IO is significantly more successful in reducing RPs' arousal, anger, and subsequent aggression in comparison with participants' involvement in distracting arithmetic tasks, their exposure to neutral auditory stimuli, and with waiting idly for a period of time $[3,15,16,38]$. The reason for such effectiveness of aggression may lie in the prevailing real-life contingencies that favor the performance of aggressive over nonaggressive responses in many noxious situations, presumably especially in cases in which the stimulation-induced arousal is labeled anger by the target of the stimulation (as opposed to, for example, fear). There is, for instance, a substantial body of evidence obtained through systematic observation in naturalistic settings, such as playgrounds, which shows that acts of revenge (justified aggression) may be very efficient in ending others' - such as playground bullies' - attacks [45,46]

It is true that there have been experiments suggesting that nonaggressive ("friendly" and even "self-punitive") responses to noxious social stimulation may lead to a decrease in arousal level $[47,48]$. However, this work merely demonstrates that certain nonaggressive responses can be conditioned to decrease the level of arousal when it is arranged, in the laboratory, that they reliably lead to threat removal. Such findings are not informative about the comparative utility of nonaggressive versus aggressive responses to noxious stimulation in the world outside the laboratory. One must remember that in the studies discussed earlier, angered participants' aggressive actions reduced their arousal level without any conditioning in the laboratory. In other words, RPs came to the laboratory with the arousal-decreasing property of their anger-induced aggressive actions already established, presumably in the course of their history of exposure to real-life 
contingencies involving noxious stimulation, aggression, and so on.

Note that nothing in the present analysis implies either that there is an inherent relationship between aggression and arousal, or that the link between aggressive behavior and autonomic changes is established by some unique process. Rather, it is merely suggested that to the extent that aggressive responses differ from the nonaggressive ones in terms of their ability to decrease arousal level, this difference may be due to the former responses' superiority in eliminating noxious stimulation in interpersonal situations.

\section{Deleterious Long-term Effects}

From a broader interpersonal, societal, and even legal perspective, the news is certainly unwelcome that aggressive retaliation is an angry person's most effective response to a provocation - in that it rapidly decreases both the aversively high level of arousal, and the emotionally and physiologically taxing degree of anger. The fact that the immediate likely result is also a reduction of the probability and intensity of this person's additional aggression - in that setting and at that time - is of little consolation, given that it is vengeful aggression that brought about the interpersonal equilibrium and relative quiescence. However, as the author recently wrote elsewhere [34], "a scientific discovery of even a disagreeable fact about human behavior or nature - made by a sound methodology and in good faith, and published in first-tier journals does not entitle [others] to pretend, ostrich-like or capriciously, that the demonstrated fact does not exist."

That ostrich-like stance is an unacceptable social and "culturological" option becomes even more obvious when one considers the longterm implications of the cathartic effect. "Unwelcome news" of the effectiveness of revenge, when provoked (including the physical variety), become "very bad news" in the long term, especially in intrafamilial dyads. The reason is to be found in the features of the cathartic effect that have been demonstrated by research and that have implications for the dyadic, especially intrafamilial, aggression sequences.

Here is what the present author wrote in 1975 [3]: "Several aspects of the present results suggest that it is likely, in the long run, that aggression breeds aggression. This may be so in spite of, or perhaps partly because of, the cathartic effect. First, if real-life contingencies favor aggressive over nonaggressive responses in anger-inducing noxious situations, and if the former are superior in decreasing the level of arousal (labeled anger) from an aversively high level, it follows that every instance in which aggression alleviates anger increases the probability that aggression will occur in future cases of anger inducement. Second, even in experimental conditions in which angered people's expression of aggression reduced the level of subsequent aggression, these subjects [research participants] evaluated the annoyer [IO] very negatively at the end of the experiment."

Konečni then mentioned that such an outcome was anticipated by Buss [49] when the latter wrote: "After the anger subsides, there remain negative language responses, consisting of resentment, [and] belief that others are threatening." Konečni continued: "This evaluative bad aftertaste may easily later lead to anger (and aggression) through the self-arousal mechanism. Third, if aggression is associated often enough in a person's life history with the elimination of others' aggression and the reduction of anger, it is likely that his [or her] aggressive responses will come to be elicited by the progressively weaker anger-inducing stimulation. An ever lower level of anger may accompany successive instances of aggression, where these instances are removed in time from each other."
Konečni then referred to an experimental condition in one of his experiments [3]: "[The above is] suggested by the interpretation of the annoyed 13-min shock cell [one of the conditions in the interpolated period, stage 2] ... in terms of the many-punishments standard adopted by subjects [RPs] who presumably delivered the majority of interpolated punishments in the virtual absence of anger [italics added]. A person who performs aggressive acts in anticipation of the onset of anger may adopt a similar standard. This seems particularly likely in the case of a prolonged dyadic interaction with a well-defined status and power structure, such as that between parent and child. Fixed behavioral sequences often characterize such relationships, and aggressive responses, if performed, are likely to be in the same mode. Aggression may then become the routine treatment, devoid of anger and other emotions and needing hardly any provocation."

This is precisely what was meant by "preemptive strikes" at the beginning of the present article, and of what scholars concentrating on the effects of distal factors in family violence [1], and those interested in adaptationist accounts of revenge [2], need to take serious cognizance: Aggression that is no longer "angry" or vengeful but cold-blooded and callously preemptive.

\section{Generality and Utility of the AABC Model}

The AABC model of anger-induced interpersonal aggression and its consequences appears to have a considerable scope. It places the link between anger and aggression in a broad emotional and motivational context, and makes it possible to integrate a large body of data within a unified theoretical framework, relating this area of research to several diverse theoretical and empirical developments. Even a cursory examination of the implications of the various details of the proposed two-way causal link between anger and aggression can illustrate the model's utility as an integrative, heuristic, and predictive tool.

An important part of the model is concerned with antecedents of anger and its effects on aggressive behavior (Section III.). The model's emphasis on anger has the function of explicitly bringing the theoretical developments in the area of emotion (such as PEEM) to bear on aggression phenomena and makes it possible that predictions be made about the (indirect) effect on aggressive behavior of a large number of factors that influence either (a) arousal level, or (b) facial expression, or (c) the cognitive-interpretive processes - because arousal, proprioceptive feedback from the facial musculature, and cognitive labeling are all considered to be important influences on the degree of anger. As a result, many isolated effects and seemingly heterogeneous antecedents of aggressive behavior can be viewed within a single conceptual scheme.

With regard to the arousal component of the model, many different stimuli and procedures, such as TV violence, physical exercise, the presence of weapons, or the sight of adults hitting dolls, to mention just a few, have arousingness as a common element and can lead to aggression when an appropriate emotional label is adopted. In addition, since the arousal-level fluctuations that are induced by noxious social stimulation have a lawful time-course, and can be affected by more than one factor simultaneously (usually in an additive manner), relatively precise predictions can be made about the differential amounts of aggressive behavior that would occur at different points in time following the instigation, as well as about the manner in which the amount of aggression would be affected by the number and type of initial arousal-raising manipulations and the subsequent presence, during the arousal-level "recovery," of factors that speed it up or slow it down. 
The model is also able to make predictions about the effect on aggressive behavior of the facial-expression component of anger. Thus, as one example, Konečni and Zellensky [50] found that by constraining angered participants' faces into a frown during the aggression phase of the experiment, they were able to increase the amount of RPs' (fictitious) aggression; in contrast, constraining angered RPs' faces into a smile led to a decrease in the amount of aggression.

As for the cognitive-labeling component of the model, it was suggested that the anger-labeling process, and consequently the amount of aggression, would almost certainly be affected by (a) attributions concerning the anger instigator's responsibility and intent, (b) a consideration of environmental and normative constraints operating on the instigator, and (c) the extent to which the situation contains elements that may lead to a misattribution of the source of experienced arousal.

Many of the empirical questions that have traditionally been treated under the heading of catharsis (Section IV.) are in the domain of the AABC model that was presented here (also see [5]). The conceptualization of the cathartic effect in the present framework may help resolve the controversy that has long surrounded this important area of research. The precise conditions necessary for the occurrence of the effect can now be specified and the various earlier failures to obtain it can be explained in terms of a relatively small set of theoretical propositions.

Finally, because arousal and affect are among the key components of the AABC model, it makes it possible to establish useful conceptual and empirical links between the work on aggression phenomena and other, seemingly unrelated, substantive areas in which arousal and affect also play a prominent role [Section VI.3.], such as certain topics in empirical (psychological) aesthetics [41,42,51,52], alcohol consumption [40], and even intergroup conflict [53]. Such efforts are but small steps to remedy the much-criticized compartmentalization of psychology.

\section{Conclusion}

The Anger-Aggression Bidirectional-Causation model's utility in the clarification of several complex issues of long standing in various scholarly domains has been demonstrated, especially: Catharsis and the "cathartic effect"; adaptationist accounts of revenge; and intrafamilial dyadic violence. This model of anger-induced interpersonal aggression and its consequences places the link between anger and aggression in a broad emotional and motivational context, and facilitates the integration of a large body of data. Moreover, and significantly, the formulation of the cathartic effect within the AABC framework helps explain (in Section VIII.) its deleterious long-term consequences in dyadic relationships and as a crucial aspect of cold-blooded revenge.

\section{References}

1. Finkernauer C, Buyukcan-Tetik A, Baumeister RF, Schoemaker K, Bartels $M$ et al. (2015) Out of control: Identifying the role of self-control strength in family violence. Current Directions in Psychological Science 24: 261-266.

2. McCullough ME, Kurzban R, Tabak BA (2013) Cognitive systems for revenge and forgiveness. Behav Brain Sci 36: 1-15.

3. Konecni VJ (1975) Annoyance, type and duration of postannoyance activity, and aggression: The "cathartic effect". J Exp Psychol Gen 104: 76-102.

4. Konecni VJ (1984) Methodological issues in human aggression research. In Kaplan RM, Konecni VJ, Novaco RW (eds.), Aggression in children and youth. Martinus Nijhoff Publishers, The Hague, Netherlands.

5. Konecni VJ (2013) Revenge: Behavioral and emotional consequences Comment in PubMed Commons below Behav Brain Sci 36: 25-26.
6. Bandura A, Ross D, Ross SA (1961) Transmission of aggression through imitation of aggressive models. comment in PubMed Commons below $\mathrm{J}$ Abnorm Soc Psychol 63: 575-582.

7. Bandura A, Ross D, Ross SA (1963) Imitation of film-mediated agressive models. J Abnorm Soc Psychol 66: 3-11.

8. Feshbach S (1955) The drive-reducing function of fantasy behavior. J Abnorm Psychol 50: 3-11.

9. Feshbach S (1961) The stimulating versus cathartic effects of a vicarious aggressive activity. J Abnorm Soc Psychol 63: 381-385.

10. Ebbesen EB, Duncan B, Konecni VJ (1975) Effects of content of verbal aggression on future verbal aggression: A field experiment. Journal of Experimental Social Psychology 11: 192-204.

11. Ax AF (1953) The physiological differentiation between fear and anger in humans. Psychosom Med 15: 433-442.

12. Schachter $H$ (1957) Pain, fear, and anger in hypertensives and normotensives a psychophysiological study. Psychosom Med 19: 17-29.

13. Averill JR (1983) Studies on anger and aggression. Implications for theories of emotion. Am Psychol 38: 1145-1160.

14. Berkowitz L (2012) A different view of anger: the cognitive-neoassociation conception of the relation of anger to aggression. Aggress Behav 38: 322-333.

15. Konecni VJ, Doob AN (1972) Catharsis through displacement of aggression. J Pers Soc Psychol 23: 379-387.

16. Konecni VJ (1975) The mediation of aggressive behavior: arousal level versus anger and cognitive labeling. J Pers Soc Psychol 32: 706-712.

17. Konecni VJ (2008) Does music induce emotion? A theoretical and methodological analysis. Psychology of Aesthetics Creativity and the Arts 2 : 115-129.

18. SCHACHTER S, SINGER JE (1962) Cognitive, social, and physiological determinants of emotional state. Psychol Rev 69: 379-399.

19. Reisenzein R (1983) The Schachter theory of emotion: two decades later. Psychol Bull 94: 239-264.

20. Konecni VJ (2010) The influence of affect on music choice. In: Juslin PN Sloboda A (eds.), Music and emotion: Theory, research, applications. Oxford University Press, Oxford, England.

21. Schachter S (1964) The interaction of cognitive and physiological determinants of emotional state. In Berkowitz L (Ed.), Advances in experimental social psychology. Academic Press, New York.

22. Zillmann D, Katcher AH, Milavsky B (1972) Excitation transfer from physical exercise to subsequent aggressive behavior. Journal of Experimental and Social Psychology 8: 247-259.

23. Konecni VJ, Spees FW (1977) A comparison of the effects of physical aggression, physical activity, and exposure to noise on subsequent aggression, with special attention to temporal and sequence parameters. University of California, San Diego.

24. Zillmann D (1971) Excitation transfer in communication-mediated aggressive behavior. Journal of Experimental Social Psychology 7: 419-434.

25. Doob AN, Climie RJ (1972) The delay of reinforcement and the effects of film violence. Journal of Experimental and Social Psychology 3: 136-142.

26. Jones EE, Davis KE (1965) From acts to dispositions: The attribution process in person perception. Advances in experimental social psychology 2: 219-266.

27. Rule BG, Nesdale AR (1976) Emotional arousal and aggressive behavior Psychol Bull 83: 851-863.

28. Laird JD (1974) Self-attribution of emotion: the effects of expressive behavior on the quality of emotional experience. J Pers Soc Psychol 29: 475-486.

29. Konecni VJ, Ebbesen EB (1976) Disinhibition versus the cathartic effect: Artifact and substance. Journal of Personality and Social Psychology 34: 352-365.

30. Bandura A (1973) Aggression: A social learning analysis. Prentice Hall, Englewood Cliffs, NJ.

31. Bushman BJ, Baumeister RF, Stack AD (1999) Catharsis, aggression, and persuasive influence: self-fulfilling or self-defeating prophecies? J Pers Soc Psychol 76: 367-376. 
Citation: Konečni VJ (2015) The Anger-Aggression Bidirectional-Causation (AABC) Model's Relevance for Dyadic Violence, Revenge and Catharsis. Abnorm Behav Psychol 1: 104. doi:10.4172/2472-0496.1000104

32. Bushman BJ (2002) Does venting anger feed or extinguish the flame? Catharsis, rumination, distraction, anger, and aggressive responding. Personality Social Psychology Bulletin 28: 724-731.

33. Bushman BJ, Bonacci AM, Pedersen WC, Vasquez EA, Miller N (2005) Chewing on it can chew you up: effects of rumination on triggered displaced aggression. J Pers Soc Psychol 88: 969-983.

34. Konecni VJ (2015) Politicized social science and human nature's disagreeable aspects: An example from the anti-catharsis aggression research. Sociology and Criminology.

35. Hokanson JE, Shetler S (1961) The effect of overt aggression on physiologica arousal level. J Abnorm Soc Psychol 63: 446-448.

36. Hokanson JE, Burgess M (1962) The effects of status, type of frustration, and aggression on vascular processes. J Abnorm Soc Psychol 65: 232-237.

37. Hokanson JE, Burgess M, Cohen MF (1963) Effects of Displaced Aggression on Systolic Blood Pressure. J Abnorm Psychol 67: 214-218.

38. Doob AN, Wood LE (1972) Catharsis and aggression: effects of annoyance and retaliation on aggressive behavior. J Pers Soc Psychol 22: 156-162.

39. Plato (1955) The republic. (Lee HDP Trans) Penguin, Harmondsworth, England.

40. Marlatt GA, Kosturn CF, Lang AR (1975) Provocation to anger and opportunity for retaliation as determinants of alcohol consumption in social drinkers. $J$ Abnorm Psychol 84: 652-659.

41. Konecni VJ, Crozier, JB, Doob (1976) Anger and expression of aggression: Effects on aesthetic preference. Scientific Aesthetics 1: 47-55.

42. Konecni VJ (1979) Determinants of aesthetic preference and effects of exposure to aesthetic stimuli: Social, emotional and cognitive factors. Progress in experimental personality research 9: 149-197.
43. Frost RO, Holmes DS (1979) Effects of displacing aggression by annoyed and nonannoyed subjects. Journal of Research in Personality 13: 221-233.

44. Konecni VJ, Manley J (1977) Effects of anger, and the level of certainty that the anger instigator has been hurt, on aggressive behavior. University of California, San Diego.

45. Patterson GR, Littman RA, Bricker W (1967) Assertive behavior in children: A step toward a theory of aggression. Monographs of the Society for Research in Child Development.

46. Patterson GR, Cobb JA (1971) A dyadic analysis of aggressive behaviors. Minnesota symposia on child psychology. University of Minnesota Press, Minneapolis, Minnesota.

47. Hokanson JE, Willers KR, Koropsak E (1968) The modification of autonomic responses during aggressive interchange. J Pers 36: 386-404.

48. Stone LJ, Hokanson JE (1969) Arousal reduction via self-punitive behavior. J Pers Soc Psychol 12: 72-79.

49. Buss AH (1961) The psychology of aggression. Wiley, New York

50. Konecni VJ, Zellensky D (1976) Effects of socially induced emotional state and proprioceptive feedback from facial expression on aggressive behavior University of California, San Diego.

51. Konecni VJ, Sargent-Pollock D (1976) Choice between melodies differing in complexity under divided-attention conditions. J Exp Psychol Hum Percep Perform 2: 347-356.

52. Konecni VJ, Sargent-Pollock D (1977) Arousal, positive and negative affect and preference for Renaissance and $20^{\text {th }}$-Century paintings. Motivation and Emotion 1: 75-93.

53. Konecni VJ (1979) The role of aversive events in the development of intergroup conflict. The social psychology of intergroup relations. Brooks/Cole, Monterey, CA 